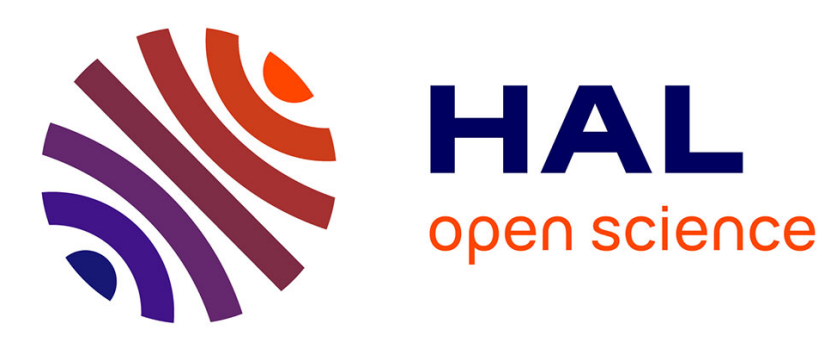

\title{
Spectral signature of a Ru(ii, iii, iv) complex: a combined experimental and theoretical investigation
}

Jacques Bonvoisin, Ilaria Ciofini

\section{To cite this version:}

Jacques Bonvoisin, Ilaria Ciofini. Spectral signature of a $\mathrm{Ru}(\mathrm{ii}$, iii, iv) complex: a combined experimental and theoretical investigation. Dalton Transactions, 2013, 42 (22), 10.1039/c3dt33043e . hal-01736348

\section{HAL Id: hal-01736348 \\ https://hal.science/hal-01736348}

Submitted on 16 Mar 2018

HAL is a multi-disciplinary open access archive for the deposit and dissemination of scientific research documents, whether they are published or not. The documents may come from teaching and research institutions in France or abroad, or from public or private research centers.
L'archive ouverte pluridisciplinaire HAL, est destinée au dépôt et à la diffusion de documents scientifiques de niveau recherche, publiés ou non, émanant des établissements d'enseignement et de recherche français ou étrangers, des laboratoires publics ou privés. 


\title{
Spectral Signature of a Ru(II, III, IV) Complex: A Combined Experimental and Theoretical Investigation
}

\author{
Jacques Bonvoisin $^{1, *}$, Ilaria Ciofini ${ }^{2}$
}

1) CEMES, CNRS UPR 8011, Nanosciences Group, 29 rue Jeanne Marvig, BP 94347, 31055

Toulouse Cedex 4, France.

2) Laboratoire d'Electrochimie, Chimie des Interfaces et Modélisation pour l'Energie, CNRS UMR7575, Ecole Nationale Supérieure de Chimie de Paris - Chimie-ParisTech, 11 rue P. et M. Curie, F75231 Paris Cedex 05

\begin{abstract}
The electronic and geometrical features of a recently synthesized ruthenium $\beta$-diketonato complex with protected ethynyl ligand $\left(\left[\mathrm{Ru}(\mathrm{dbm})_{2}(\mathrm{acac}-\mathrm{TIPSA})\right], \mathrm{dbm}=\right.$ dibenzoylmethanate ion, acac-TIPSA = 3-(Trisopropylsilyl)acetylene-2,4-pentanedionate ion), building block for molecular spintronic devices, were analyzed as a function of its oxidation degree using Density Functional Theory (DFT) and Time Dependent DFT (TD-DFT), for ground and excited state properties, respectively, and compared to the available experimental data.

The UV-Vis spectral signature of native $\mathrm{Ru}(\mathrm{III})$ neutral form computed at TD-DFT level was compared to those of the oxidized $\mathrm{Ru}(\mathrm{IV})$ and reduced $\mathrm{Ru}(\mathrm{II})$ ones, allowing to clearly identify the nature of all bands occurring in this spectral region and thus providing important photophysical insights for the use of this complex as building block in polynuclear organometallic mixed valence molecular systems able to perform a swapping operation under light control.
\end{abstract}




\section{Introduction}

These last years, molecular spintronics ${ }^{1}$ has attracted the interest of many scientists emerging as an hot topic in fundamental science in particular for its potentialities related to quantum computing. ${ }^{2,3}$ Several molecular or atomic spin systems have been proposed to construct quantum gates. ${ }^{4-9}$

In this context, a challenge is represented by the conception of single molecules acting as a calculating unit by themselves, that is as devices at the molecular level. ${ }^{10}$

Very recently, one of us conceived a generic 4-center organometallic mixed valence molecular system able to perform a swapping operation controlled by light. ${ }^{11}$ This 4-center system is made of a tetranuclear ruthenium system $\mathrm{Ru}(\mathrm{III})_{3} \mathrm{Ru}(\mathrm{IV})$. Several mononuclear precursors corresponding to the building blocks necessary to construct this target molecule have been already synthesized and characterized in detail. ${ }^{12-15}$ Among those, a new ruthenium $\beta$-diketonato complex with protected ethynyl ligand $\left[\mathrm{Ru}(\mathrm{dbm})_{2}(\mathrm{acac}-\mathrm{TIPSA})\right](\mathrm{dbm}=$ dibenzoylmethanate ion, acac-TIPSA = 3(Trisopropylsilyl)acetylene-2,4-pentanedionate ion), schematically depicted in Scheme 1, has been recently synthesized and fully characterized at the experimental level. ${ }^{15}$

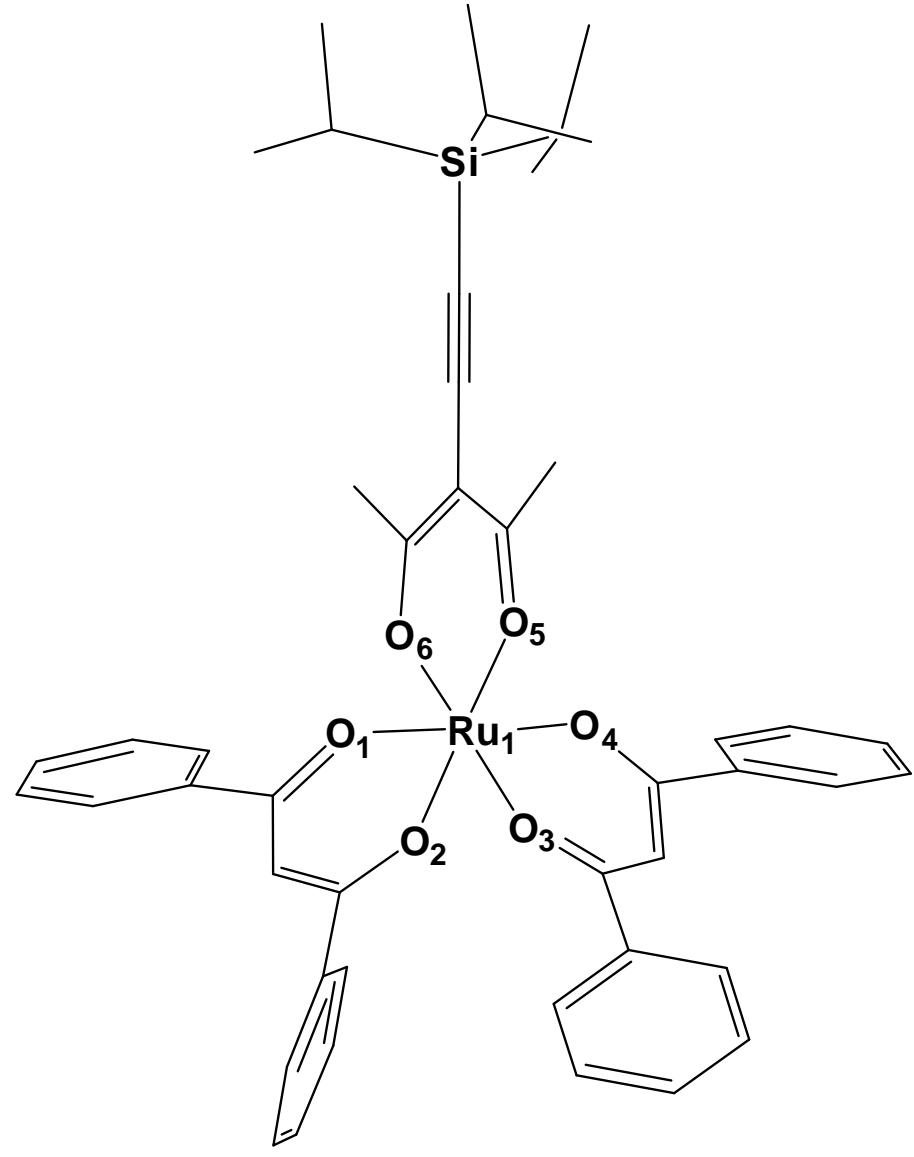

Scheme 1. Schematic representation and labeling scheme of the systems analyzed.

The stable form of this complex is neutral, with the ruthenium atom in the oxidation state +3 since $\mathrm{dbm}$ and acac-TIPSA are mono-anionic ligands. This complex can be reversibly reduced or oxidized by electrolysis at constant potential $(-1 \mathrm{~V}$ vs SCE for the reduction and $+1.25 \mathrm{~V}$ vs SCE for the 
oxidation). For each of these forms the UV-Vis data were collected and they are reported in Figure 1. More details about the experimental UV-Vis data can be found in our previous work. ${ }^{15}$

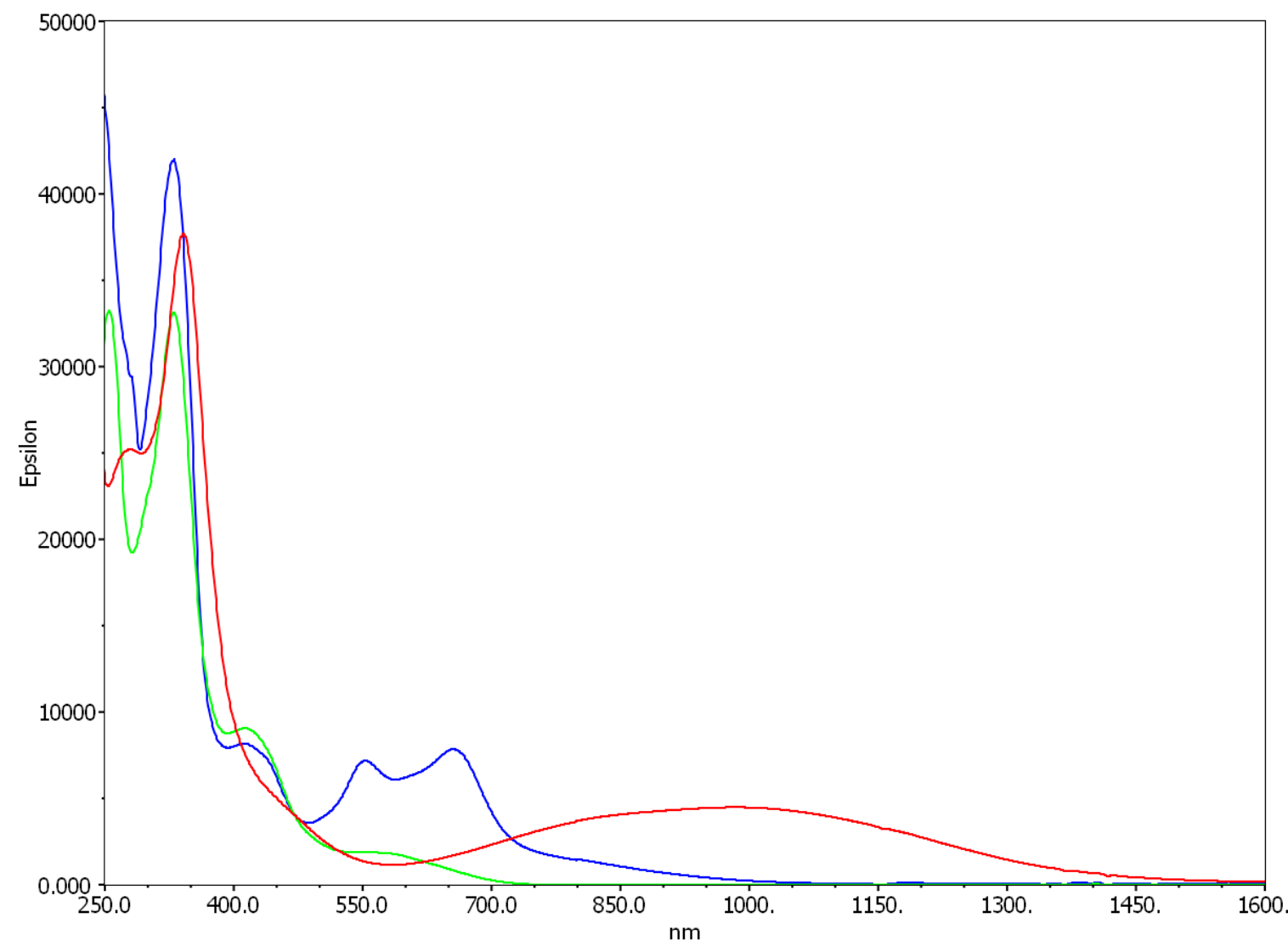

Figure 1. Experimental spectra recorded in $\mathrm{CH}_{2} \mathrm{Cl}_{2}$ for the different $\left[\mathrm{Ru}(\mathrm{dbm})_{2}(\mathrm{acac}-\mathrm{TIPSA})\right]$ forms: native/Ru(III) (green line), reduced/Ru(II) (blue line) and oxidized/Ru(IV) (red line). Reduced and oxidized species have been obtained by electrolysis at constant potentials $(-1$ V/SCE and +1.25 V/SCE, respectively) in $\mathrm{CH}_{2} \mathrm{Cl}_{2}$, TBAH 0.1M.

The goal of the present contribution is to clearly describe the electronic structure of the different forms of the title compound and to assign all main bands which appear in the UV-Vis spectra with the aim of identifying the spectral signature of the degree of oxidation of the ruthenium atom within the complex. This information will be of relevance when aiming at understanding or predicting the photophysical behavior of higher nuclearity compounds that shall be used as molecular spintronic devices.

Furthermore, an accurate knowledge of the electronic structure of the mononuclear ruthenium complex at the ground state is particularly important to better interpret the STM image of this single molecule on a surface, technique which may be used to better characterize the complexes whose one aims to use them as single molecule devices.

In this respect, methods rooted on Density Functional Theory (DFT) and on Time dependent DFT (TD-DFT) appear as particularly suited in order to get a clear-cut picture of the electronic structure of 
both the ground and the vertical excited states, and, thus, to get the necessary understanding of the electronic features of these rather complex molecular systems.

Several works have already demonstrated the capability and the accuracy of DFT for the description of the electronic and geometrical features of complexes containing transition metal ions and, more particularly of Ru complexes. As a matter of fact several studies reported in literature, both fully theoretical and mixed theoretical and experimental, focused on $\mathrm{Ru}(\mathrm{II})$ complexes of technological (such as dyes for Dye Sensitized Solar Cells) ${ }^{16-18}$, biological (such as DNA intercalators) ${ }^{19,20}$ and fundamental interest (such as compounds for photoinduced charge separation) ${ }^{21-24}$, testified that, using sufficiently accurate exchange correlation potentials, a quantitative description of the experimental photophysical properties can be obtained. In particular, hybrid exchange and correlation functionals appeared as particularly well suited to obtained reliable structural and electronic features of $\mathrm{Ru}$ complexes at the ground state. ${ }^{25}$ Analogously several recent works demonstrated the remarkable accuracy of TD-DFT in conjunction with the same exchange and correlation functionals for the description of the spectral features of $\mathrm{Ru}$ (II) containing metal complexes and, especially of the transitions of Metal to Ligand Character (MLCT) with limited though space character occurring in the visible spectral range. ${ }^{26}$ Moreover, the use of hybrid exchange and correlation functionals allows for a balanced description of MLCT and Ligand Centered (LC) states thus allowing for a trustable assignment of intermingled experimental spectra or the use of TD-DFT for the in-silico design of new systems.

Since TD-DFT methods and computationally more expensive ab-initio approaches, such as postHartree Fock methods, provide a similar description of the photophysical properties of Ru containing complexes, not surpringly the former are currently extensively used for the investigation of the electronic properties at both the ground and the excited state of large d-transition metal complexes. ${ }^{25-26}$ Remarkably, theoretical works concerning $\mathrm{Ru}(\mathrm{III})$ and $\mathrm{Ru}(\mathrm{IV})$ complexes are less numerous than those devoted to $\mathrm{Ru}$ (II) complexes and mainly related to the investigation of catalytically active compounds (both of synthetic or biomimetic relevance). ${ }^{27-31}$

The paper is structured as follows: after a brief description of the computational approaches used (section 2), the electronic and geometrical features are discussed in section 3.1 together with the absorption properties of each compound (section 3.2). Finally, some general conclusions, concerning the accuracy of the methods and the spectroscopic signature of the Ru centers, are drawn in last section.

\section{Computational details}

All calculations were performed with the Gaussian09 program package. ${ }^{32}$ The hybrid PBE0 functional $^{33}$ casting $25 \%$ of Hartree-Fock exchange in the GGA PBE functional, ${ }^{34,35}$ was used throughout both for structural optimization and for excited state calculations performed at TD-DFT level. For both structural optimization and excited state calculations, all atoms were described using a 
double zeta quality basis set (LANL2DZ) ${ }^{36}$ For the Ru atom the same basis set and the corresponding pseudopotential were applied. ${ }^{37-39}$

In the case of the $\mathrm{Ru}(\mathrm{IV})$ complex, structural optimization were performed both for the singlet and triplet spin state. This last one (triplet) resulted as the most stable spin state (of roughly $10 \mathrm{kcal} / \mathrm{mol}$ ). Optical transitions were computed in order to cover the full UV-Vis range. Simulated spectra reported in Figures were obtained from the computed vertical transition energies and oscillator strengths by a using a convolution with Gaussian functions (half height width: $40 \mathrm{~nm}$ ) with Gabedit software. ${ }^{40}$ The MO drawings were obtained with GaussView 5.0. ${ }^{41}$

Solvent effects (dichloromethane, DCM) were included using the Polarizable Continuum Model (PCM) both for ground and excited state calculations, as available in the Gaussian code (CPCM) ${ }^{42,43}$ only in the case of the $\mathrm{Ru}(\mathrm{II})$ complex. Structural and absorption data computed at this level of theory are reported in Supported Information for comparison purposes.

\section{Results and discussion}

\subsection{Geometrical and electronic structural features}

The computed geometrical parameters for $\mathrm{Ru}$ complex in its native $\mathrm{Ru}(\mathrm{III})$, oxidized $\mathrm{Ru}(\mathrm{IV})$ and reduced $\mathrm{Ru}$ (II) form together with the experimental Xray data available for the $\mathrm{Ru}(\mathrm{III})$ species are reported in Table 1, while the labeling scheme adopted is reported in Scheme 1.

First of all, one can note a fairly good agreement between the computed and the experimental data available for the $\mathrm{Ru}(\mathrm{III})$ complex. The coordination sphere of the $\mathrm{Ru}(\mathrm{III})$ is rather well reproduced by the calculations since the difference between computed and experimental Ru-O bonds is always below $2 \%$ (that is $0.03 \AA$ ). Furthermore, the shorter Ru-O bonds experimentally observed in the case of the oxygen atoms of the acac-TIPSA ligand $\left(\mathrm{Ru}_{-} \mathrm{O}_{5}\right.$ and $\mathrm{Ru}-\mathrm{O}_{6}$ in Table 1) are overall correctly reproduced by the calculations. As expected the Ru ion keeps a pseudo octahedral coordination, only slightly distorted due the presence of non-equivalent ligands. The computed distances are also in rather good agreement with the experimental ones previously reported in literature for similar compounds. ${ }^{14,15,44-51}$ From a structural point of view, not surprisingly oxidation seems mainly to affect $\mathrm{Ru}$ coordination sphere, following the expected contraction of the Ru-O bonds when one goes from $\mathrm{Ru}(\mathrm{II})_{\mathrm{S}=0}$ to $\mathrm{Ru}(\mathrm{IV})_{\mathrm{S}=1}$, the average Ru-O bond length varying from $2.042 \AA$ (computed for $\mathrm{Ru}$ (II)) to $1.986 \AA$ (computed for $\mathrm{Ru}(\mathrm{IV})$ ). On the other hand, since the oxidation is essentially centered on the metal, the ligands are not subject to very relevant structural changes, especially for what concerns the TIPSA moiety. 
Table 1 Computed geometrical parameters (bond lengths in $\AA$, angles in degrees) together with the available experimental data.

\begin{tabular}{lccccc}
\hline & $\mathbf{R u}(\mathbf{I I})$ & $\mathbf{R u}(\mathbf{I I I})$ & $\begin{array}{c}\mathbf{R u}(\mathbf{I I I}) \\
\langle\mathbf{e x p}\rangle\end{array}$ & $\begin{array}{c}\mathbf{R u}(\mathbf{I V}) \\
\mathbf{S}=\mathbf{0}\end{array}$ & $\begin{array}{c}\mathbf{R u}(\mathbf{I V}) \\
\mathbf{S}=\mathbf{1}\end{array}$ \\
\hline $\mathrm{Ru}_{1}-\mathrm{O}_{4}$ & 2.039 & 2.007 & 1.994 & 1.988 & 1.986 \\
$\mathrm{Ru}_{1}-\mathrm{O}_{1}$ & 2.039 & 2.008 & 2.003 & 2.015 & 1.986 \\
$\mathrm{Ru}_{1}-\mathrm{O}_{3}$ & 2.033 & 2.027 & 1.998 & 1.983 & 1.976 \\
$\mathrm{Ru}_{1}-\mathrm{O}_{2}$ & 2.033 & 2.03 & 2.024 & 1.951 & 1.976 \\
$\mathrm{Ru}_{1}-\mathrm{O}_{6}$ & 2.053 & 2.019 & 1.998 & 2.02 & 1.997 \\
$\mathrm{Ru}_{1}-\mathrm{O}_{5}$ & 2.053 & 2.019 & 1.996 & 1.966 & 1.996 \\
$\left\langle\mathrm{Ru}_{-}-\mathrm{O}>\right.$ & 2.042 & 2.018 & 2.002 & 1.987 & 1.986 \\
$\mathrm{C} \equiv \mathrm{C}$ & 1.237 & 1.233 & 1.208 & 1.235 & 1.234 \\
$\mathrm{O}_{6}-\mathrm{Ru}_{1}-\mathrm{O}_{5}$ & 90.2 & 91.5 & 92.7 & 87.0 & 86.9 \\
$\mathrm{O}_{4}-\mathrm{Ru}_{1}-\mathrm{O}_{3}$ & 92.2 & 89.9 & 91.9 & 93.3 & 88.9 \\
$\mathrm{O}_{1}-\mathrm{Ru}_{1}-\mathrm{O}_{2}$ & 92.1 & 89.6 & 91.9 & 87.9 & 88.9 \\
$\mathrm{O}_{1}-\mathrm{Ru}_{1}-\mathrm{O}_{6}$ & 89.6 & 89.3 & 92.7 & 89.9 & 90.7 \\
$\mathrm{O}_{5}-\mathrm{Ru}_{1}-\mathrm{O}_{4}$ & 88.9 & 88.3 & 88.5 & 87.5 & 90.9 \\
$\mathrm{O}_{3}-\mathrm{Ru}_{1}-\mathrm{O}_{2}$ & 89.2 & 90.1 & 92.9 & 88.7 & 89.5 \\
\hline
\end{tabular}

The MO isodensity surfaces and energies computed for the $\mathrm{d}^{6}$ (i.e. reduced $\mathrm{Ru}(\mathrm{II})$ ) species are reported in Figure 2.

The computed orbital splitting corresponds to what expected for a $\mathrm{Ru}$ (II) ion in octahedral environment : the three highest occupied MOs are very closely lying in energy and display a large contribution on the metal center. These orbitals basically correspond to the $t_{2 g}$ set of the d orbitals of a $\mathrm{d}^{6}$ ion in octahedral environment while the loss of perfect degeneracy is due to the presence of different ligands in the Ru coordination sphere. Below these orbitals, a doubly occupied MO with large contribution from atomic orbitals centered on the TIPSA moiety is found, thus underlying the donor character of this ligand. On the other hand the lowest lying unoccupied orbitals (from the LUMO to the LUMO+3) show contributions mainly arising from the dbm moieties. 


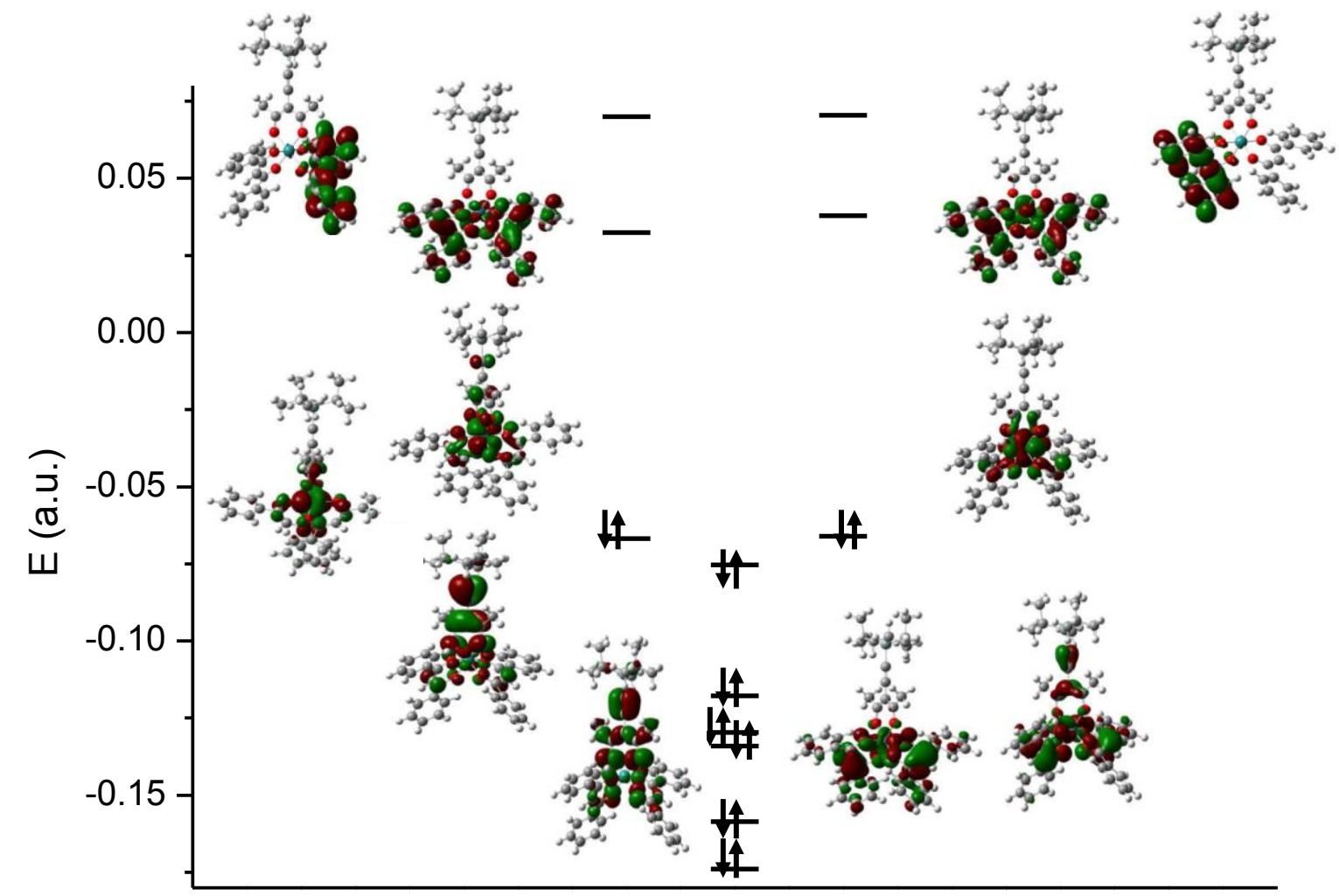

Figure 2. Orbital energies (in a.u.) and isodensity plots (contour value 0.025 a.u.) computed for the reduced $\left[\mathrm{Ru}(\mathrm{II})(\mathrm{dbm})_{2}(\mathrm{acac}-\mathrm{TIPSA})\right]^{-}$species.

This orbital picture doesn't change a lot in the case of the native Ru(III) species (whose MO diagram is reported in Supporting Information, Figure SI.1) although the metal character of the highest occupied MO decreases as a consequence of the mainly metal centered oxidation that stabilize the metal centered MO. The fact that redox processes take place essentially at the Ru atom is qualitatively confirmed by the inspection of the Mulliken charges (and Mulliken Atomic Spin population in the case of open shell systems, that is the $\mathrm{Ru}(\mathrm{III})$ and $\mathrm{Ru}(\mathrm{IV})_{\mathrm{S}=1}$ ). Indeed, computed charges varies from 0.44 in the case of the $\mathrm{Ru}(\mathrm{II})$ species to 0.62 and 0.82 for the $\mathrm{Ru}(\mathrm{III})$ and $\mathrm{Ru}(\mathrm{IV})$, species, respectively. The localization of the hole(s) on the $\mathrm{Ru}$ atom for the $\mathrm{Ru}(\mathrm{III})$ complex after its oxidation from the $\mathrm{Ru}(\mathrm{II}) \mathrm{d}^{6}$ closed shell electronic configuration, is confirmed by the computed Mulliken Atomic Spin Density (0.84 e-) actually corresponding to the presence of an unpaired electron on the $\mathrm{Ru}$ atom. Analogously the oxidation from $\mathrm{Ru}(\mathrm{III})$ to $\mathrm{Ru}(\mathrm{IV})$ seems mainly to take place on the $\mathrm{Ru}$ center, the spin density computed on this latter being, for the $\mathrm{Ru}(\mathrm{IV})_{\mathrm{S}=1}$ complex, of $1.25 \mathrm{e}-$. 
Oxidation of the $\mathrm{Ru}(\mathrm{III})$ species yields to the $\mathrm{Ru}(\mathrm{IV})$ species for which the intermediate spin triplet state $(S=1)$ is indeed computed to be more stable than the corresponding singlet state of roughly 10 $\mathrm{kcal} / \mathrm{mol}$.

Several examples of six-coordinated $\mathrm{Ru}(\mathrm{IV})$ complexes displaying either a diamagnetic or a paramagnetic ground state exist in literature. ${ }^{27-31}$ The recent theoretical paper of Gonzalez and collaborators shows how DFT is indeed able to provide a realistic picture of the spin state ordering in the case of $\mathrm{Ru}(\mathrm{IV})$ compounds. ${ }^{27}$ The results obtained in this work are coherent with the conclusions of Gonzalez work concerning the stabilization of the intermediate spin state $(S=1)$ in presence of $\mathrm{O}$ or $\mathrm{S}$ containing ligands and to the MO diagram computed for the $\mathrm{Ru}(\mathrm{II})$ species (Figure 2) displaying to pseudo-degenerate orbitals of $\mathrm{d} \pi$ character as highest occupied MOs. A careful analysis of MOs (Figure SI.2) computed for the Ru(IV) compound actually shows that the highest occupied MOs display a more marked ligand character, the $\mathrm{d}$ center orbitals being shifted more significantly to lower energies as a consequence of the metal centered oxidation.

More interestingly the presence of a diamagnetic $(S=0)$ or paramagnetic $(S=1)$ ground state is associated with important structural reorganization. In particular, the angle between O-Ru-O plane and O-C-C-C-O acac-TIPSA one is computed to be $29^{\circ}$ for diamagnetic $(\mathrm{S}=0)$ compound while is reduced to $0^{\circ}$ in the case of the $(\mathrm{S}=1)$ intermediate spin state (Figure SI.3). Analysis of computed Mulliken atomic charges qualitatively shows that in the case of the diamagnetic $\mathrm{Ru}(\mathrm{IV})_{\mathrm{S}=0}$ species the second oxidation involves to a slightly larger extent than in the case of the $\mathrm{Ru}(\mathrm{IV})_{\mathrm{S}=1}$ also the ligands (and in particular the acac-TIPSA moiety) which may explain the difference in structure computed for the $\mathrm{Ru}(\mathrm{IV})_{\mathrm{S}=1}$ and $\mathrm{Ru}(\mathrm{IV})_{\mathrm{S}=0}$ complexes.

\subsection{Absorption properties}

As previously reported, ${ }^{15}$ the experimental spectra of the neutral, $\mathrm{Ru}(\mathrm{III})$, species is dominated by three intense bands, two in the UV domain (at $258 \mathrm{~nm}$ and $330 \mathrm{~nm}$, respectively) and one in the visible range (at $413 \mathrm{~nm}$ ), while a weaker band appears at lower energies (at $570 \mathrm{~nm}$ ).

If reduction (and oxidation) of this species has small impact in the UV domain, the most intense bands being only slightly shifted in energy although being significantly changed in relative intensity, in the visible and near IR domains the redox signature of both oxidation and reduction is clear.

Upon reduction to $\mathrm{Ru}(\mathrm{II})$, a rise in absorbance in the visible range is observed due to the emergence of two new bands at 554 and $656 \mathrm{~nm}$, respectively. On the other hand upon oxidation a broad band appears in the near-IR region, centered at $980 \mathrm{~nm}$.

The experimentally measured spectra, together with the corresponding computed transition energies and simulated spectra for the reduced, native and oxidized species are reported in Figure 3-5, respectively.

An overall quantitative agreement between the observed and computed absorption energies can be remarked. The difference in energy between the maxima in experimental spectra and the computed transition energies are all below the $0.15 \mathrm{eV}$ threshold, which is indeed considered the accuracy that 
one can reasonably expect at this level of theory. Beside the relative intensity of the picks is well reproduced both within the same species as well as when comparing the complex at different degree of oxidation. Thus, we can conclude that TD-DFT calculations are able to capture all main spectral features related to the oxidation or reduction processes.

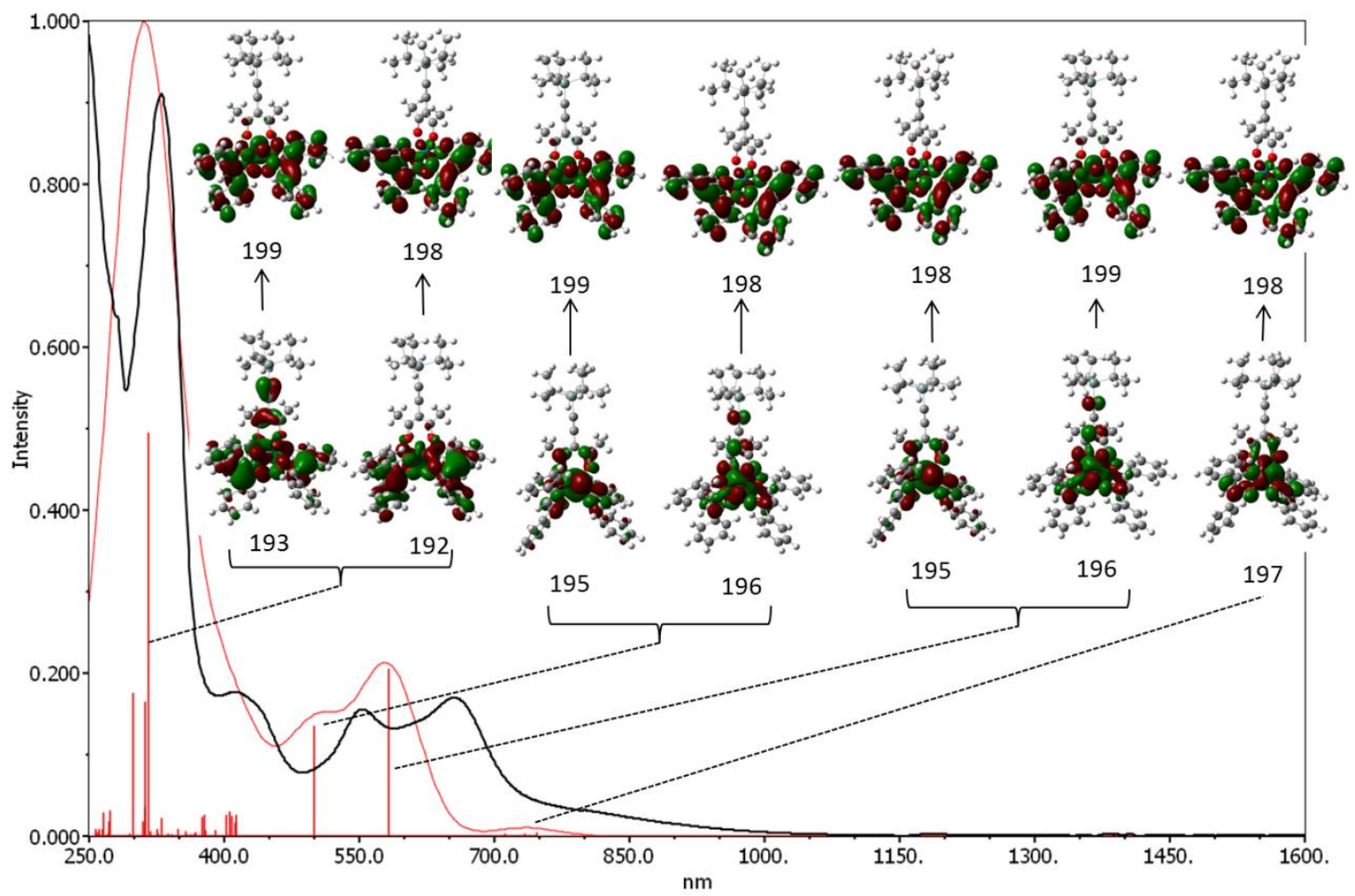

Figure 3. Experimental (black line) normalized absorption spectra of the reduced ( $\mathrm{Ru}(\mathrm{II}))$ $\left[\mathrm{Ru}(\mathrm{II})(\mathrm{dbm})_{2}(\mathrm{acac}-\mathrm{TIPSA})\right]^{-1}$ complex together with the corresponding computed vertical transition energies and simulated spectra (red line) 


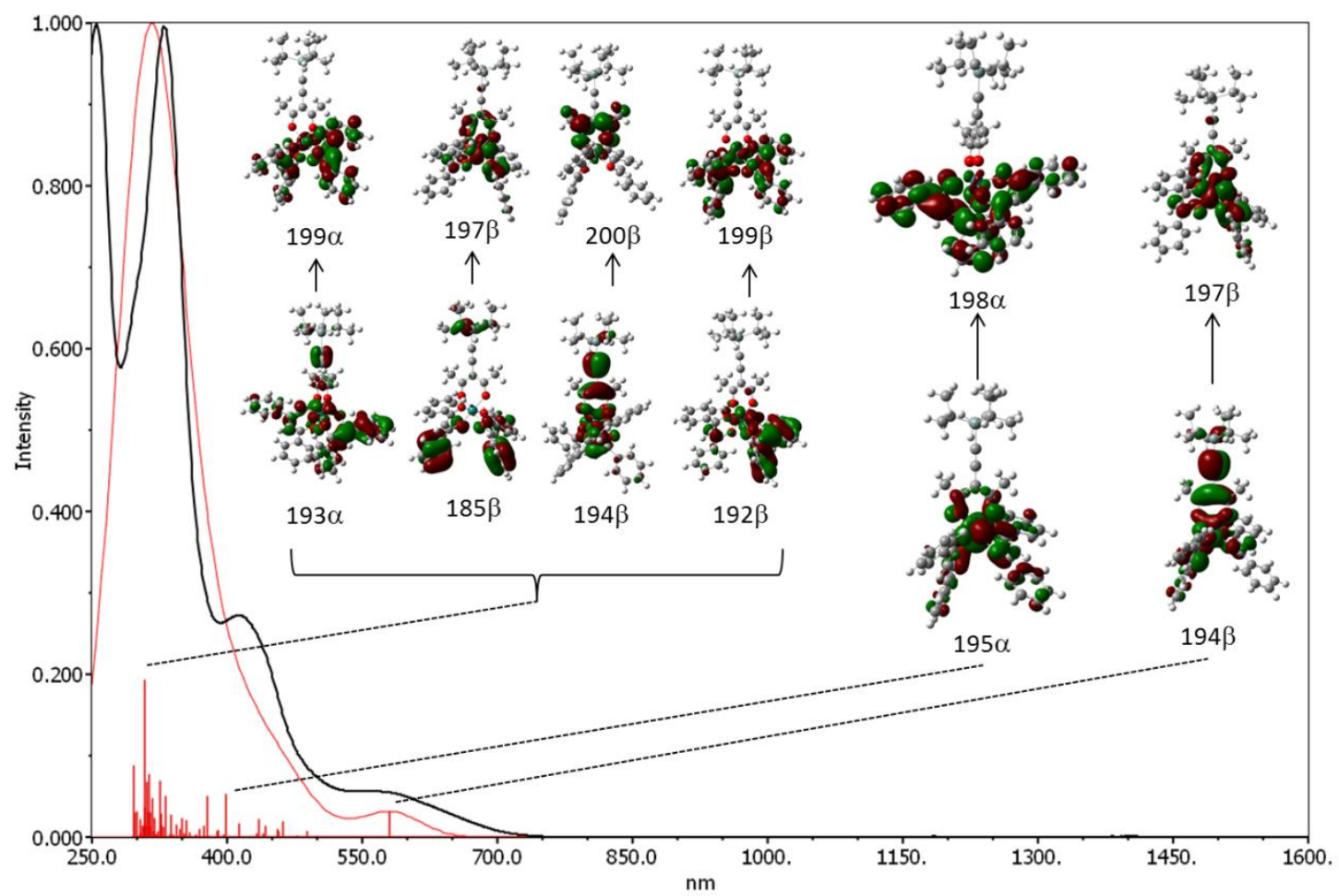

Figure 4. Experimental (black line) normalized absorption spectra of the native (Ru(III)) $\left[\mathrm{Ru}(\mathrm{III})(\mathrm{dbm})_{2}(\mathrm{acac}-\mathrm{TIPSA})\right]^{0}$ complex together with the corresponding computed vertical transition energies and simulated spectra (red line)

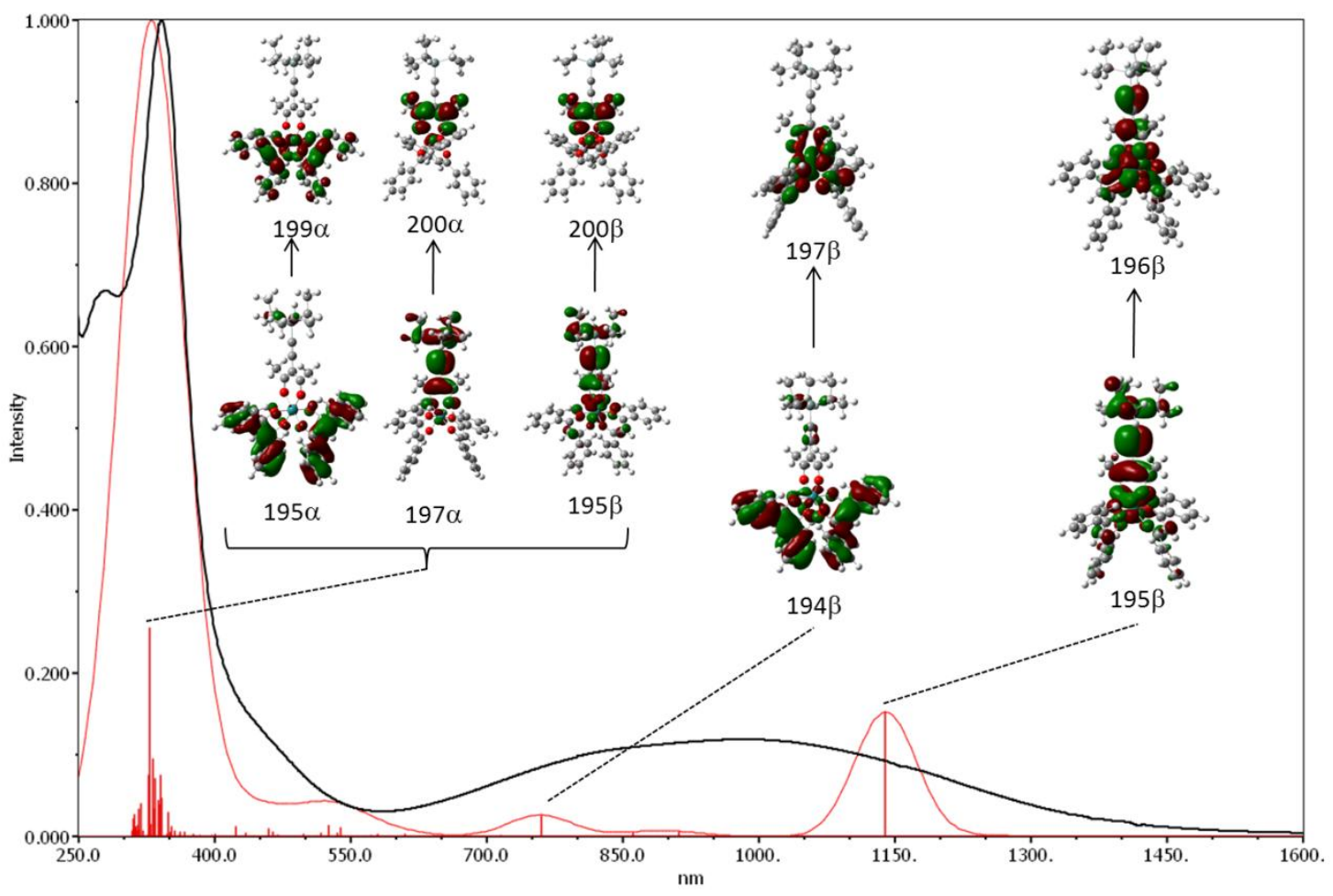

Figure 5. Experimental (black line) normalized absorption spectra of the oxidized (Ru(IV)) $\left[\mathrm{Ru}(\mathrm{IV})(\mathrm{dbm})_{2}(\mathrm{acac}-\mathrm{TIPSA})\right]^{+1}$ complex together with the corresponding computed vertical transition energies and simulated spectra for $\mathrm{Ru}(\mathrm{IV})_{\mathrm{S}=1}$ (red line) 
The band experimentally measured at $330 \mathrm{~nm}$ in the case of the neutral compound (Figure 4, Ru(III)) is practically unchanged upon reduction (Figure 3) while slightly (roughly $10 \mathrm{~nm}$ ) red shifted upon oxidation (Figure 5).

This band is indeed computed at $309 \mathrm{~nm}$ in the case of the $\mathrm{Ru}(\mathrm{III})$ species and red shifted at 316 and $329 \mathrm{~nm}$ for the $\mathrm{Ru}(\mathrm{II})$ and $\mathrm{Ru}(\mathrm{IV})$ complexes, respectively. Therefore both the sign and magnitude of the shifts observed upon both reduction and oxidation are almost quantitatively reproduced by the calculations.

Analyzing the nature molecular orbitals involved in all these transitions, these latter can be unambiguously assigned as ligand centred (LC) excitations, with contribution stemming from orbitals centered both on the dbm ligands and a non-negligible Inter Ligand Charge Transfer (ILCT) character associated to mono-electronic excitations from orbitals centered on the acac-TIPSA ligand to orbitals of the dbm moieties, which should, indeed, be not very sensitive to the redox processes occurring at the metal center.

On the other hand, since most of the transitions involving metal orbitals occur in the visible and nearIR spectral range it is not surprising that this latter contain the spectral signature of the oxidation degree of the $\mathrm{Ru}$ atom within the complex.

In the visible range, the neutral $\mathrm{Ru}(\mathrm{III})$ complex experimentally shows a rather broad band at $570 \mathrm{~nm}$ and a more intense band at $413 \mathrm{~nm}$, while no absorption is present in the near-IR region. From our calculations (Figure 4) is rather clear that the lowest energy transition (computed at $580 \mathrm{~nm}$ in very good agreement with the experimental maximum observed at $570 \mathrm{~nm}$ ) has a significant Ligand to Metal Charge Transfer Character (LMCT). From an orbital point of view, this transition mainly corresponds to a monoelectronic excitation from a doubly occupied orbital centered mainly on the acac and ethynyl moieties of the acac-TIPSA ligand to an essentially metal centered orbital.

Two 'classical' Metal to Ligand Charge Transfer Transitions (MLCT) are indeed computed at 399 and $378 \mathrm{~nm}$ in rather good agreement with the experimental spectra showing a single MCLT band at 413 $\mathrm{nm}$, together with a number of other, less intense transitions always of MLCT character in the same spectral region. The oscillator strength associated to the most intense MLCT transitions is higher than that computed for the LMCT transition (0.05 vs 0.03 for the MCLTs and the LMCT, respectively), in agreement with the observed relative intensity of the bands associated to such transitions. The MLCT transitions occur from doubly occupied molecular orbitals centered on the metal to ligands (dbm) centered orbitals. Beside an overestimation of the absolute transition energy ascribable to the lack of solvent effects in our simulation, which is indeed still compatible with the level of theory here applied, most probably the energetic splitting between the two computed MLCT (of $0.174 \mathrm{eV}$ ) is slightly overestimated.

Upon reduction to a negatively charged Ru(II) complex (Figure 3), the LMCT band disappears and two transitions are computed in the visible range, at 500 and $582 \mathrm{~nm}$, with an intensity ratio of 2:3. 
These two transitions, of MCLT character involving mainly ligand orbitals centered on the dbm moieties fit very well the experimental spectra consisting, in this spectral region, of two transitions at 554 and $656 \mathrm{~nm}$, respectively. Indeed, in the experimental spectra, a broad band in the near IR region (i.e. around $750 \mathrm{~nm}$ ) is observed. This broad band can be ascribed to a HOMO-LUMO transition of MCLT character, which is computed at $748 \mathrm{~nm}$ with quite low intensity as depicted in Figure 3 or a to spin forbidden transition $(\mathrm{S}=0$ to $\mathrm{S}=1$ ) or to a combination of both. In order to qualitative estimate the energy of the spin forbidden transition, this latter was computed using a $\triangle \mathrm{SCF}$ approach at $979 \mathrm{~nm}$ (in the gas phase) and $898 \mathrm{~nm}$ when simulating solvent effects (here DCM) by a continuum polarizable (PCM approach), ${ }^{52}$ that is at significantly lower energies that what experimentally observed.

The band experimentally observed at $413 \mathrm{~nm}$, and practically unaffected by reduction from $\mathrm{Ru}$ (III) to $\mathrm{Ru}(\mathrm{II})$, is still ascribed to a series of low intensity transitions of MLCT character computed around 400 $\mathrm{nm}$ and mostly involving dbm centered MOs as vacant orbitals.

Overall, one can thus conclude that reduction to the $\mathrm{Ru}$ (II) complex implies an increase of absorption in the visible range mostly associated to the rising of MCLT type transitions, while the UV part of the spectra, involving ILCT transitions, is not strongly perturbed.

The situation is clearly different when the $\mathrm{Ru}(\mathrm{III})$ complex is oxidized to yield the positively charged $\mathrm{Ru}(\mathrm{IV})$ species (Figure 5). Indeed, both from experimental and computed spectra, a drastic decrease of absorption in the visible range and increase in the near-IR region are observed. The decrease is associated to the absence of the MLCT transitions occurring at lower energy (that is the one computed around $600 \mathrm{~nm}$ for the $\mathrm{Ru}(\mathrm{II})$ ) mainly due to the shift at lower energy of metal centered orbitals, as previously discussed for the $\mathrm{Ru}(\mathrm{III})$ and $\mathrm{Ru}(\mathrm{IV})$ species.

Indeed, the positively charged $\mathrm{Ru}(\mathrm{IV})$ species is characterized by two transitions occurring in the nearIR domain (at 761 and $1140 \mathrm{~nm}$, respectively) both of marked LMCT character. These two transitions are both contributing to the broad band observed in the near-IR region with absorption maximum at around $980 \mathrm{~nm}$. If both the computed transitions possess an LMCT character (Figure 5) the ligand centered orbitals involved are indeed significantly different. In particular, the most intense LMCT transition, that is the one computed at $1140 \mathrm{~nm}$ shows an acac-TIPSA to Ru character while the ligand orbitals involved in the higher energy LMCT (i.e. the one at $761 \mathrm{~nm}$ ) are mostly centered on the dbm moieties. Finally, it is worth noting that the singlet $\mathrm{Ru}(\mathrm{IV})$ species, computed to be less stable of roughly $10 \mathrm{kcal} / \mathrm{mol}$, also shows a very similar spectrum (reported in Figure SI.5 and SI.6) to the triplet $\mathrm{Ru}(\mathrm{IV})$ complex only the low lying LMCT transition being perturbed as a consequence of the different oxidation pattern already discussed for the two species. Therefore, the concomitant presence of the $S=0$ and $S=1 \mathrm{Ru}(\mathrm{IV})$ species cannot be ruled out on the basis of the sole analysis of their spectral features.

\section{Conclusions}


The electronic and geometrical properties of a recently synthesized ruthenium $\beta$-diketonato complex with protected ethynyl ligand $\left(\left[\mathrm{Ru}(\mathrm{dbm})_{2}(\mathrm{acac}-\mathrm{TIPSA})\right], \mathrm{dbm}=\right.$ dibenzoylmethanate ion, acac-TIPSA = 3-(Trisopropylsilyl)acetylene-2,4-pentanedionate ion) were interpreted as a function of its oxidation degree using Density Functional Theory (DFT) and Time Dependent DFT (TD-DFT), for ground and excited state properties, respectively, and compared to the available experimental data.

The UV-Vis spectral signature of native $\mathrm{Ru}(\mathrm{III})$ neutral form computed at TD-DFT level was compared to those of the oxidized ( $\mathrm{Ru}(\mathrm{IV}))$ and reduced $(\mathrm{Ru}(\mathrm{II}))$ species. The results obtained show how the increase in absorption in the near-IR region observed upon oxidation of the native (Ru(III)) system is related to the presence of low lying LMCT states involving both the TIPSA and the dbm ligands.

LMCT transitions mainly involving the TIPSA ligand are indeed present also in the case of the native system although shifted to higher energy (in the visible region around $550 \mathrm{~nm}$ ), while, as expected completely absent in the case of the reduced $\mathrm{Ru}$ (II) compound. A sizable absorption in the visible domain dominated by classical MLCT transitions is indeed observed for this latter ( $\mathrm{Ru}(\mathrm{II}))$.

Finally, in the near UV domain all forms show a very similar spectral behavior dominated by LC transitions, not sensible to the metal degree of oxidation.

The clear identification of the nature of all bands occurring in these systems obtained by comparison of the present TD-DFT results with the experimental data provides important photophysical insights of relevance in the case of the use of this complex as building block in polynuclear organometallic mixed valence molecular systems able to perform a swapping operation under light control

\section{Acknowledgements:}

This work was granted access to the HPC resources of CALMIP under the allocation 2012-[1206]. This work has been made possible through the CNRS thematic school 'Modélisation moléculaire des propriétés chimico-physiques par des méthodes de chimie quantique - ENSCM - june 2011'

\section{References}

1. S. Sanvito, Chem. Soc. Rev., 2011, 40, 3336-3355.

2. J. Lehmann, A. Gaita-Arino, E. Coronado and D. Loss, J. Mater. Chem., 2009, 19, 1672-1677.

3. F. Troiani and M. Affronte, Chem. Soc. Rev., 2011, 40, 3119-3129.

4. G. Aromi, D. Aguila, P. Gamez, F. Luis and O. Roubeau, Chem. Soc. Rev., 2012, 41, 537-546.

5. F. Luis, A. Repolles, M. J. Martinez-Perez, D. Aguila, O. Roubeau, D. Zueco, P. J. Alonso, M. Evangelisti, A. Camon, J. Sese, L. A. Barrios and G. Aromi, Phys. Rev. Lett., 2011, 107.

6. J. Lehmann, A. Gaita-Arino, E. Coronado and D. Loss, Nature Nanotech., 2007, 2, 312-317.

7. L. Bogani and W. Wernsdorfer, Nat Mater, 2008, 7, 179-186.

8. G. A. Timco, S. Carretta, F. Troiani, F. Tuna, R. J. Pritchard, C. A. Muryn, E. J. L. Mclnnes, A. Ghirri, A. Candini, P. Santini, G. Amoretti, M. Affronte and R. E. P. Winpenny, Nature Nanotech., 2009, 4, 173-178.

9. A. A. Khajetoorians, J. Wiebe, B. Chilian and R. Wiesendanger, Science, 2011, 332, 1062-1064.

10. R. Stadler, S. Ami, C. Joachim and M. Forshaw, Nanotechnology, 2004, 15, S115-S121. 
11. M. Hliwa, J. Bonvoisin and C. Joachim, Advances in Atom and Molecule Machines, 2013, DOI: 10.1007/1978-1003-1642-33137-33134_33118.

12. C. Viala and J. Bonvoisin, Inorg. Chim. Acta, 2010, 363, 1409-1414.

13. S. Munery, J. Jaud and J. Bonvoisin, Inorg. Chem. Commun., 2008, 11, 975-977.

14. S. Munery, N. Ratel-Ramond, Y. Benjalal, L. Vernisse, O. Guillermet, X. Bouju, R. Coratger and J. Bonvoisin, Eur. J. Inorg. Chem., 2011, 2698-2705.

15. L. Vernisse, S. Munery, N. Ratel-Ramond, Y. Benjalal, O. Guillermet, X. Bouju, R. Coratger and J. Bonvoisin, J. Phys. Chem. C, 2012, 116, 13715-13721.

16. F. Labat, I. Ciofini, H. P. Hratchian, M. J. Frisch, K. Raghavachari and C. Adamo, J. Phys. Chem. C, 2011, 115, 4297-4306.

17. A. Monari, X. Assfeld, M. Beley and P. C. Gros, J. Phys. Chem. A, 2011, 115, 3596-3603.

18. M. K. Nazeeruddin, F. De Angelis, S. Fantacci, A. Selloni, G. Viscardi, P. Liska, S. Ito, T. Bessho and M. Gratzel, J. Am. Chem. Soc., 2005, 127, 16835-16847.

19. D. Ambrosek, P. F. Loos, X. Assfeld and C. Daniel, J. Inorg. Biochem., 2010, 104, 893-901.

20. M. Atsumi, L. Gonzalez and C. Daniel, J Photoch Photobio A, 2007, 190, 310-320.

21. I. Ciofini, P. P. Laine, F. Bedioui and C. Adamo, J. Am. Chem. Soc., 2004, 126, 10763-10777.

22. J. Fortage, F. Puntoriero, F. Tuyeras, G. Dupeyre, A. Arrigo, I. Ciofini, P. P. Laine and S. Campagna, Inorg. Chem., 2012, 51, 5342-5352.

23. P. P. Laine, I. Ciofini, P. Ochsenbein, E. Amouyal, C. Adamo and F. Bedioui, Chem-Eur J, 2005, 11, 3711-3727.

24. P. P. Laine, F. Loiseau, S. Campagna, I. Ciofini and C. Adamo, Inorg. Chem., 2006, 45, 55385551.

25. A. Vlcek and S. Zalis, Coord. Chem. Rev., 2007, 251, 258-287.

26. C. Daniel, Coord. Chem. Rev., 2003, 238, 143-166.

27. E. Gonzalez, P. J. Brothers and A. Ghosh, J. Phys. Chem. B, 2010, 114, 15380-15388.

28. T. Kojima, Y. Hirai, T. Ishizuka, Y. Shiota, K. Yoshizawa, K. Ikemura, T. Ogura and S. Fukuzumi, Angew. Chem. Int. Edit., 2010, 49, 8449-8453.

29. D. Schroder and S. Shaik, Angew. Chem. Int. Edit., 2011, 50, 3850-3851.

30. T. Kojima and S. Fukuzumi, Angew. Chem. Int. Edit., 2011, 50, 3852-3853.

31. T. Kojima, K. Nakayama, K. Ikemura, T. Ogura and S. Fukuzumi, J. Am. Chem. Soc., 2011, 133, 11692-11700.

32. Gaussian09, Revision A.02, M. J. Frisch, G. W. Trucks, H. B. Schlegel, G. E. Scuseria, M. A. Robb, J. R. Cheeseman, G. Scalmani, V. Barone, B. Mennucci, G. A. Petersson, H. Nakatsuji, M. Caricato, X. Li, H. P. Hratchian, A. F. Izmaylov, J. Bloino, G. Zheng, J. L. Sonnenberg, M. Hada, M. Ehara, K. Toyota, R. Fukuda, J. Hasegawa, M. Ishida, T. Nakajima, Y. Honda, O. Kitao, H. Nakai, T. Vreven, J. Montgomery, J. A., J. E. Peralta, F. Ogliaro, M. Bearpark, J. J. Heyd, E. Brothers, K. N. Kudin, V. N. Staroverov, R. Kobayashi, J. Normand, K. Raghavachari, A. Rendell, J. C. Burant, S. S. Iyengar, J. Tomasi, M. Cossi, N. Rega, J. M. Millam, M. Klene, J. E. Knox, J. B. Cross, V. Bakken, C. Adamo, J. Jaramillo, R. Gomperts, R. E. Stratmann, O. Yazyev, A. J. Austin, R. Cammi, C. Pomelli, J. W. Ochterski, R. L. Martin, K. Morokuma, V. G. Zakrzewski, G. A. Voth, P. Salvador, J. J. Dannenberg, S. Dapprich, A. D. Daniels, Ö. Farkas, J. B. Foresman, J. V. Ortiz, J. Cioslowski and D. J. Fox, Gaussian, Inc., Wallingford CT, 2009.

33. C. Adamo and V. Barone, J. Chem. Phys., 1999, 110, 6158-6170.

34. J. P. Perdew, K. Burke and M. Ernzerhof, Phys. Rev. Lett., 1997, 78, 1396-1396.

35. J. P. Perdew, K. Burke and M. Ernzerhof, Phys. Rev. Lett., 1996, 77, 3865-3868.

36. T. H. Dunning and P. J. Hay, ed. H. F. Schaefer, Plenum, New York, 1976, vol. III, pp. 1-28.

37. P. J. Hay and W. R. Wadt, J. Chem. Phys., 1985, 82, 270-283.

38. P. J. Hay and W. R. Wadt, J. Chem. Phys., 1985, 82, 299-310.

39. W. R. Wadt and P. J. Hay, J. Chem. Phys., 1985, 82, 284-298.

40. Gabedit-A graphical user Interface for computational chemistry softwares, A. R. Allouche, J Comput Chem, 2011, 32, 174-182. 
41. GaussView, Version 5, R. Dennington, T. Keith and J. Millam, Semichem Inc., Shawnee Mission KS, 2009.

42. V. Barone and M. Cossi, J. Phys. Chem. A, 1998, 102, 1995-2001.

43. M. Cossi, N. Rega, G. Scalmani and V. Barone, J. Comput. Chem., 2003, 24, 669-681.

44. S. Aynetchi, P. B. Hitchcock, E. A. Seddon, K. R. Seddon, Y. Z. Yousif, J. A. Zora and K. Stuckey, Inorg. Chim. Acta, 1986, 113, L7-L9.

45. I. R. Baird, S. J. Rettig, B. R. James and K. A. Skov, Can. J. Chem.-Rev. Can. Chim., 1999, 77, 1821-1833.

46. Y. Hoshino, F. Ozaki, S. Igarashi and Y. Yukawa, Inorg. Chim. Acta, 2011, 374, 654-659.

47. Y. Hoshino, Y. Yukawa, A. Endo, K. Shimizu and G. P. Sato, Chem. Lett., 1987, 845-848.

48. T. S. Knowles, M. E. Howells, B. J. Howlin, G. W. Smith and C. A. Amodio, Polyhedron, 1994, 13, 2197-2203.

49. T. S. Knowles, B. J. Howlin, J. R. Jones, D. C. Povey and C. A. Amodio, Polyhedron, 1993, 12, 2921-2924.

50. P. A. Reynolds, J. W. Cable, A. N. Sobolev and B. N. Figgis, J. Chem. Soc., Dalton Trans., 1998, 559-569.

51. P. Wang, J. E. Miller, L. M. Henling, C. L. Stern, N. L. Frank, A. L. Eckermann and T. J. Meade, Inorg. Chem., 2007, 46, 9853-9862.

52. J. Tomasi, B. Mennucci and R. Cammi, Chem. Rev., 2005, 105, 2999-3093. 